\author{
Professor Leonardo BADEA, PhD \\ E-mail: leonardo.badea@bnro.ro \\ Valahia University of Targoviste \\ Associate Professor Andreea-Daniela MORARU, PhD \\ E-mail: amoraru@univ-ovidius.ro \\ Lecturer Constantin ILIE, PhD \\ Associate Professor Cristina DUHNEA, PhD \\ E-mail: cristinaduhnea@univ-ovidius.ro \\ Ovidius University of Constanta \\ Associate Professor Iulian PANAIT, PhD \\ E-mail: Iulian.panait@gmail.com \\ Department of Economic Studies \\ "Hyperion" University of Bucharest
}

\title{
CUSTOMER SATISFACTION WITH BANKING SERVICES. SIMULATING THE INFLUENCE OF CUSTOMER SATISFACTION DETERMINANTS USING ARTIFICIAL NEURAL NETWORK ALGORITHMS
}

Abstract. The current conditions brought customer satisfaction and its' determinants to the attention of bank management and the concern to develop and implement specific decision-making instruments with regard to customer satisfaction generated a plethora of approaches. The present research focuses on customer satisfaction and a set of customer satisfaction determinants to reveal the directions for improvement. To attain the research objectives, several artificial neuronal network algorithms were tested to find the most suitable one for the data.The results indicated the Quick propagation algorithm as most suitable. The most influential input over the training results and, thus, over the values simulated for the outputs was the tariffs component, with an influence of over a quarter of the entire input influence. The convenience and environment components' influences followed, with around 19\% each, while the lowest influences were exhibited by quality and e-banking with around $16 \%$ each. As the most influential component, tariffs revealed its potential as a source of competitive advantage. Surprisingly, quality and e-banking recorded the lowest levels of influence on the general satisfaction level, indicating that further research and better policy communication are needed in this area.

Keywords: Customer satisfaction analysis, Customer satisfaction criteria, Artificial Neural Networks, Banking services.

JEL Classification: G21, G41, M31 
Leonardo Badea, Andreea-Daniela Moraru, Constantin Ilie, Cristina Duhnea, Iulian Panait

\section{Introduction}

The banking services sector is constantly under pressure to adapt to the challenges brought by the past decades to maintain profitability. The accelerated digitalization, the advent of new competitors (fintech companies and shadow banking operators), the deregulation of the industry, as well the changes in customer expectations concerning service quality cannot be ignored in the elaboration of business and marketing strategies.

Globally, banks struggle to maintain market share and improve performance indicators. To attain this objective, the management has to take into account that in most national markets (except perhaps for some less developed economies) the digitalization determined the increase of the intrinsic competition within the banking industry even further intensified by the fintech companies and shadow banking institutions. On the other hand, also in most local markets, customers turned more sophisticated and demanding - the financial literacy level increased, the access to information became more facile, and the generalized use of the Internet allowed customers to compare the banks' service offers. On the other hand, the banking activity does not allow a significant differentiation of the service offer, thus bringing to light the importance of customer satisfaction determinants and the interest of the bank management to identify directions to improve to ensure customer retention.

The last three decades proved that the length of the economic cycles shortened and the recession periods when bank loans are less accessed (as a traditional banking activity) are more frequent. Therefore, one of the directions for the banks to improve economic performance is to maintain customer satisfaction levels and to adapt service provision by introducing digital instruments and generalizing e-banking and mobile banking services. Moreover, the customer-bank relationship changed with regard to service provision expectations. If in the past, this relationship focused in most cases on one particular service, at present, customers demand service packages that respond better to their financial service needs.

Academia paid serious attention to the investigation of factors influencing satisfaction and numerous specialists have proposed models to analyse the relationship between the level of customer satisfaction and its determinants. These studies proved all the more useful as customers chose banks based not only on service quality but also on their capacity to deliver complex services, assistance, and counselling through well-trained employees, simultaneously reducing waiting and processing times.

If concerning the categories of factors that influence customer satisfaction there is a certain consensus, the intensity of these influences and the hierarchy of their importance remain under debate. Studies focusing on different national 
Customer Satisfaction with Banking Services. Simulating the Influence of

Customer Satisfaction Determinants Using Artificial Neural Network Algorithms

markets or regions in a certain market revealed results that differedboth from market to market and in time.

The Romanian banking industry follows the global trend as far as the development strategies are concerned. According to the latest National Bank report, the banking sector cumulates $75 \%$ of the financial system assets, but the financial intermediation level is low and droppedfor 10 consecutive years reaching $25.2 \%$ in December 2019 and rose only marginally above 27\% at the end of 2020. According to the same report, the banks in Romania continued to reduce operational expenses ${ }^{1}$, partially linked with the digitalization trend. Therefore, in 2019 , the network of physical bank units decreased by $6.4 \%$, while the number of employees decreased by $1.2 \%$, thuscontinuing the tendency of the previous years.

The retail focus of the Romanian banking industry is confirmed by the annual dynamic of households'loans which although decreased in 2019 (an annual increase of 7.6\% in December 2019 as compared to 9.2\% in December 2018), remains higher than that of nonfinancial companies' loans (6.4\% in December 2019; 6.3\% in December 2018). Also, the Romanian banking system financing is based in a significant proportion on attracting households' deposits and only marginally on other financing sources including own emissions of debt instruments (nongovernmental residents' deposits represent 69\% of the assets; the annual dynamic was12\%in December 2019as compared to 9\% in December 2018).

Recent trends in the Romanian banking industry as well as the scarcity of consistent studies regarding customer satisfaction with banking services justify the interest to focus on the determinants of satisfaction and the liaisons between these factors and the general level of customer satisfaction with banking services.

Therefore, the objectives of the paper may be summarized as follows:

- To investigate the global and partial levels of customer satisfaction with banking services, given a set of customer satisfaction criteria;

- To determine the importance of customer satisfaction criteria and subcriteria in the global satisfaction level;

- To identify the satisfaction criteria which require improvement to achieve a higher level of customer satisfaction.

\section{Customer satisfaction with banking services}

Banking services as a subject of consumer satisfaction investigation is a distinct research direction. Given the complex nature of this type of services, a topical discussion is the identification of the determinants that influence customer satisfaction with banking services (Bahia and Nantel, 2000; Belasand Gabcova,

1 The staff costs (the most important component of the operational costs) increased $(47.2 \%)$, as did the administrative costs $(38.5 \%)$ which determined an increase in the operational costs in 2019. 
Leonardo Badea, Andreea-Daniela Moraru, Constantin Ilie, Cristina Duhnea, Iulian Panait

2014; Belas and Gabcova, 2016; Keisidou et al., 2013; Mylonakis, 2009; Ozatac et al., 2016;Siskos and Grigoroudis, 2002).

Previous studies focused on identifying research methods and were conducted on single banks or entire banking systems, at a local, regional or national level. Researchers decided upon different sets of satisfaction determinants, with the most common aim to obtain factor hierarchies. The research revealed mixed results. Belas and Gabcova (2014) revealed e-banking as the most important factor affecting satisfaction. Keisidou et al. (2013) found that brand credibility and tangibles had a significant effect on customer satisfaction. In the study of Mylonakis (2009) the most important factors were location, personnel (manners), punctuality and trust, and technological modernization (e-commerce). Ozatac et al. (2016) showed that customer satisfaction depended on good and firm relations and on building trust between customers and bank employees.

Other research directions focused on the relationship between customer satisfaction with banking services and related concepts such as customer loyalty (Hallowell, 1996; Casalo et al., 2008; Yilmaz et al., 2018) or customer retention (Rust and Zahorik, 1993; Gan et al., 2006; SigitParawansa, 2018).

\section{Research methodology}

\subsection{Sampling and data}

Taking into account previous research as well as the particularities of the Romanian customer behaviour, a construct of five customer satisfaction determinants was set: convenience (CON), environment (ENV), quality (QUA), tariffs (RAT), and e-banking (EBA). Four of the five determinants have several sub-criteria, as follows: convenience (bank location, distance to the bank, parking spaces availability, ATM availability), environment (office furniture, equipment, cleanness, personnel physical appearance, bank atmosphere), quality (bank confidence, personnel promptitude, safety of operations, personnel solicitude), ebanking (availability of services, services performance). This construct of customer satisfaction determinants has been the object of previous research by Ilie et al., 2017; Moraru and Duhnea, 2018a; Moraru and Duhnea, 2018b.

The data were obtained from a descriptive quantitative research based on a questionnaire.The questionnaire comprised a general, socio-demographic section (age, level of education, gender, professional status, residence, and level of revenues) and a second section aimed at obtaining information about the five above-mentioned customer satisfaction determinants with banking services. The evaluation was conducted using five-point semantic differentials (from 1 - very unsatisfactory to 5 - very satisfactory).

The research was conducted in two counties in the South-East of Romania, in the historical province of Dobrudja, Constanta and Tulcea, between September and November 2019. The Dobrudja region has a significant contribution to the 
Customer Satisfaction with Banking Services. Simulating the Influence of

Customer Satisfaction Determinants Using Artificial Neural Network Algorithms

country's GDP, ranging between 5.4\% and 5.25\% during 2014-2019 (Romanian National Institute of Statistics Statistical Database).

The sample size $(\mathrm{N})$ was determined using the formula of Daniel and Cross (2013), considering the adult population, aged above 18 years in the province under survey $(873,969)$ (County Statistics Directorate), $\mathrm{z}_{\alpha}=1.96$, corresponding to a confidence level of $95 \%, e=0.03, p=0.5$. The resulting sample size was 1,066 . 1,200 questionnaires were randomly distributed using interview operators in the targeted region.The questionnaire targeted sensitive information such as income level and therefore the anonymity was ensured.1,098 questionnaires were returned filled in, thus yielding a 0.08 rate of non-responses. After a preliminary analysis regarding the completeness of the information, the data analysis was eventually conducted on 1,094 questionnaires.

\subsection{Method}

Given the heterogeneity of the data the authors have chosen as appropriate the feedforward artificial neural network. Four training algorithms were used. The first three employed the AlyudaNeuroIntelligence Software: Quick propagation(heuristic modification of the back propagation algorithm)(Fahlman, 1999), Levenberg-Marquardt (LM) (Lourakis, 2005), and Quasi-Newton (Dennis and More, 1977). The fourth algorithm was programed in Python software (Google Colab Notebooksscikit module) as a Multi-layer Perceptron (MLP) with backpropagation algorithm with hyperbolic tangent for hidden neurons activation and stochastic gradient descent as solver for weight optimization. While the AlyudaNeuroIntelligence Software is a software ready to be implemented with only a few features that can be changed, in Python the algorithm can be modified and new functions and featurescan be implemented. Moreover, Python can implement deep learning (DL) algorithms, such as Convolutional Neural Network (CNN) useful especially considering the heterogeneity of the data. The objective of present research is to determine which of the "classical" ANN can classify best the data with high nonlinearity. Thus, the MLP will embrace common features to the other three algorithms, but with a few specific changes.

The methodology contained the following steps, for all the variants: 1.Data Analysis; 2.Data Pre-processing; 3.Network architecture design; 4.Training; 5.Testing.

The initial data and ANN structure remained constant in the training process for each of the evaluated algorithms.

The first step is the data analysis that is determined by the software for all algorithms. For the Alyuda software the results of the analysis are presented below as the software's Analysis Report:

- 6 columns and 993 rows analyzed (5 rows disabled as Data anomalies: 5 numeric outliers);

- 6 columns and 988 rows accepted for neural network training; 
Leonardo Badea, Andreea-Daniela Moraru, Constantin Ilie, Cristina Duhnea, Iulian Panait

- 2 categorical columns (Each value of a categorical data represents a certain category): RAT, SAT;

- 4 numeric columns: CON, ENV, QUA, EBA;

- Output column: SAT;

- Data partition method: random;

- Data partition results: 672 records to Training set (68.02\%), 158 records to Validation set (15.99\%), 158 records to Test set (15.99\%).

As it can be seen the automate analysis discards 5 rows of the data sets (5 rows disabled as Data anomalies). From a more a careful look the five datasets contain missing or misspelled data. Thus, from the initial 1094 initial datasets only 988 were used in pre-processing and training. 101 of them will be used for external testing (never fed to the ANN previously) that stand as a criterion for the best suited algorithm. Also, here the ANN separates data into types: numeric and categorical.

The second step, the pre-processing makes the adjustment of the data before it is fed to a neural network. Pre-processing changes the data to make it fit for neural network (e.g., scaling and encoding categories into numeric values) and improves the data quality (e.g., filtering outliers and approximating missing values). The results are presented in Alyuda's Pre-processing Report:

- Columns before preprocessing: 6;

- Columns after preprocessing: 14 ;

- Input columns scaling range: [-1..1];

- Output column(s) scaling range: [0..1]

- Numeric columns scaling parameters: CON: 0.5, ENV: 0.5, QUA: 0.666667, EBA: 0.5;

- Categorical column encoding parameters: RAT: One-of-5, SAT: One-of5.

Table 1 contains data features after pre-processing.

Table 1. Features of each parameter after pre-processing. Alyuda software

\begin{tabular}{|c|c|c|c|c|c|c|c|c|c|c|}
\hline $\begin{array}{l}\text { No. } \\
\text { Crt. }\end{array}$ & Parameter & $\begin{array}{c}\text { Column } \\
\text { type }\end{array}$ & Format & $\begin{array}{c}\begin{array}{c}\text { Scaling } \\
\text { range }\end{array} \\
\end{array}$ & $\begin{array}{l}\text { Encoded } \\
\text { into }\end{array}$ & Min & Max & Mean & $\begin{array}{c}\text { Std. } \\
\text { deviation }\end{array}$ & $\begin{array}{l}\begin{array}{l}\text { Scaling } \\
\text { factor }\end{array} \\
\end{array}$ \\
\hline 1. & $\mathrm{CON}$ & input & $\begin{array}{c}\text { numer } \\
\text { ical }\end{array}$ & {$[-1 . .1]$} & \multirow{3}{*}{$\begin{array}{c}1 \\
\text { column }\end{array}$} & 1 & 5 & 3.76 & 0.793 & 0.50 \\
\hline 2. & ENV & input & $\begin{array}{c}\text { numer } \\
\text { ical }\end{array}$ & {$[-1 . .1]$} & & 1 & 5 & 3.64 & 0.812 & 0.50 \\
\hline 3. & QUA & input & $\begin{array}{c}\text { numer } \\
\text { ical }\end{array}$ & {$[-1 . .1]$} & & 2 & 5 & 4.14 & 0.64 & 0.67 \\
\hline 4. & RAT & input & $\begin{array}{l}\text { catego } \\
\text { rical }\end{array}$ & {$[-1 . .1]$} & $\begin{array}{c}5 \\
\text { columns }\end{array}$ & - & - & - & - & - \\
\hline 5. & EBA & input & $\begin{array}{c}\text { numer } \\
\text { ical }\end{array}$ & {$[-1 . .1]$} & $\begin{array}{c}1 \\
\text { column }\end{array}$ & 1 & 5 & 3.44 & 1.249 & 0.50 \\
\hline 6. & SAT & output & $\begin{array}{l}\text { catego } \\
\text { rical }\end{array}$ & {$[0 . .1]$} & $\begin{array}{c}5 \\
\text { columns }\end{array}$ & - & - & - & - & - \\
\hline
\end{tabular}

Source: Authors' simulation with AlyudaNeuroIntelligence 
Customer Satisfaction with Banking Services. Simulating the Influence of

Customer Satisfaction Determinants Using Artificial Neural Network Algorithms

The Python also uses pre-processing for the preparation of data. The Min-Max normalization uses the following mathematical formulation:

$$
\mathrm{x}_{\text {scaled }}=\frac{\mathrm{x}-\min (\mathrm{x})}{\max (\mathrm{x})-\min (\mathrm{x})}(1)
$$

where $\mathrm{x}$ is a single feature/variable vector.

The back-propagation can be more stable and even faster after normalization. The results of pre-processing in Python determined a different architecture of ANN as it didn't disperse the RAT into 5 columns, but kept it into one column (figure 1b)).

The experiences have shown that the type of 2-layer ANN has the capability to estimate any non-linear continuous functions with a confident degree of accuracy for a sufficient number of neurons in the hidden layer.

The following architectures were chosen (figure 1a)) from several structures of ANN, after trying several designs and considering the best one with the smallest training error, without taking into account other ANN features. Also, the 9 inputs and the 5 outputs are imposed by the ANN analysis that considers RAT and SAT categorical variables (as they have only value $\{1,2,3,4,5\}$ ) and split them into 5 new columns. The 9-17-5 architecture was used for all the three Alyuda algorithms.

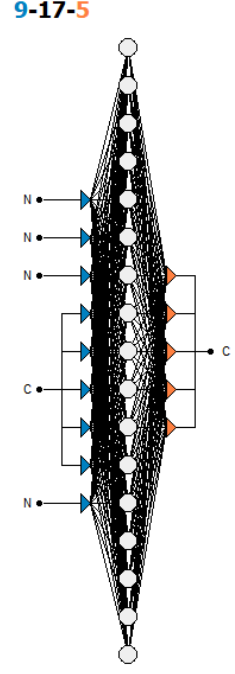

a)

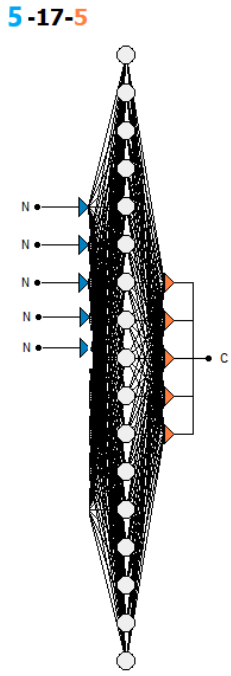

b)

Figure 1. Network architecture: a) network in Alyuda software; b) network in Python Source: Authors' simulation

The chosen architecture has the following features:

- Architecture selected manually;

- [9-17-5] architecture selected for training;

- Hidden layers activation function: Hyperbolic tangent;

- Output parameters: SAT; 
Leonardo Badea, Andreea-Daniela Moraru, Constantin Ilie, Cristina Duhnea, Iulian Panait

- Error function: Cross-entropy. For Levenberg-Marquardt training algorithm, error function: Sum-of squares. Levenberg-Marquardt training algorithm only accepts certain functions for error and activation.

- Activation function: SoftMax. For Levenberg-Marquardt training algorithm, error function: Logistic;

- Classification model: Winner-takes-all;

Even though the literature refers to the logistic function as the best activation function for the hidden layers, for the backpropagation algorithm, given the authors' previous expertise the hyperbolic tangent was chosen as the activation function. Also, the training conditions must be definedbefore the training process implementation (table 2).

Table 2. Training conditions for each of the four algorithms. Alyuda software and Python

\begin{tabular}{|c|c|c|c|c|c|}
\hline No.Crt. & $\begin{array}{l}\text { Training } \\
\text { algorithms }\end{array}$ & $\begin{array}{c}\text { Learning } \\
\text { rate }\end{array}$ & \multicolumn{2}{|c|}{ Specific training features } & $\begin{array}{c}\text { Stopping training } \\
\text { conditions }\end{array}$ \\
\hline 1. & $\begin{array}{l}\text { Quick } \\
\text { propagation }\end{array}$ & 0.1 & $\begin{array}{c}\text { Quick propagation } \\
\text { coefficient }\end{array}$ & 0.75 & \multirow{3}{*}{$\begin{array}{c}\mathrm{CCR}=99.989998 \\
\text { (tracked on training) }\end{array}$} \\
\hline 2. & $\begin{array}{l}\text { Levenberg- } \\
\text { Marquardt }\end{array}$ & $\begin{array}{c}\text { Not } \\
\text { necessary }\end{array}$ & \multicolumn{2}{|c|}{$\begin{array}{l}\text { Local minima avoidance for } \\
\text { Levenberg-Marquardt }\end{array}$} & \\
\hline 3. & Quasi-Newton & $\begin{array}{c}\text { Not } \\
\text { necessary }\end{array}$ & \multicolumn{2}{|c|}{ Not necessary } & \\
\hline 4. & $\begin{array}{l}\text { Python } \\
\text { Multilayer } \\
\text { Perceptron } \\
\text { (MLP) }\end{array}$ & 0.009 & \multicolumn{2}{|c|}{$\begin{array}{l}\text { Stochastic gradient descent for } \\
\text { weight optimization }\end{array}$} & $\begin{array}{l}\text { Max iterations = } \\
10000 \\
\text { No error change for } \\
100 \text { iterations (for } \\
\text { error } 1 \times 10^{-5} \text { ) }\end{array}$ \\
\hline
\end{tabular}

Source: Authors' simulation

CCR stands for Correct Classification Rate and is used in classification tasks as a qualitative characteristic. This rate is calculated by dividing the number of correctly recognized records by the total number of records. CCR is measured in relative units or as percentage. The high value of CCR was imposed in order to determine the lowest possible network error, for the best training results, also the low learning rate, especially for MLP was necessary for avoiding the local minima blockage for all the algorithms.

\section{Research results}

The descriptive statistics of the variables are presented in Appendix 1.

After the training process,the results considered were network errors (figure 2), the confusion matrix (figure 3 ) and several training characteristics (table 3). 
Customer Satisfaction with Banking Services. Simulating the Influence of

Customer Satisfaction Determinants Using Artificial Neural Network Algorithms

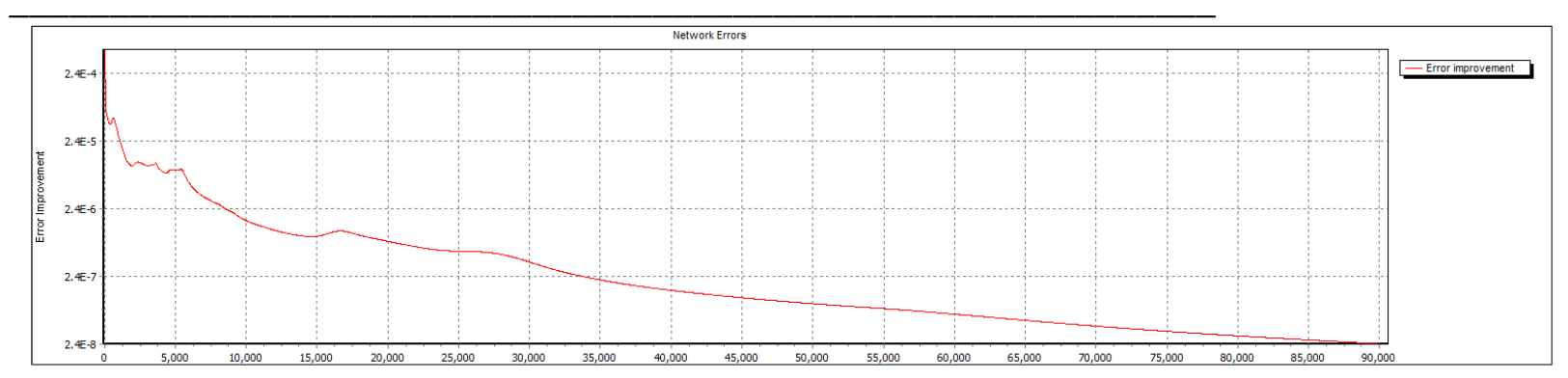

a)

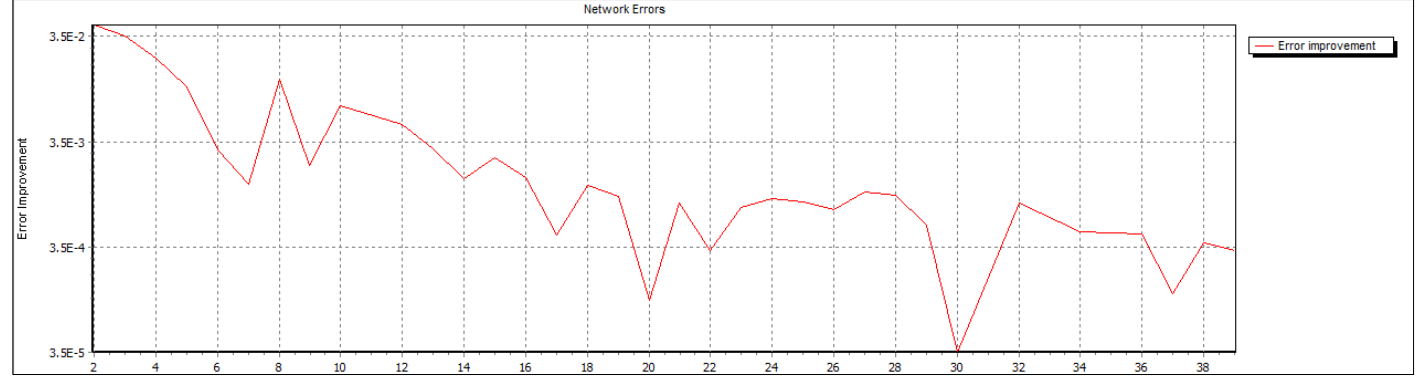

b)

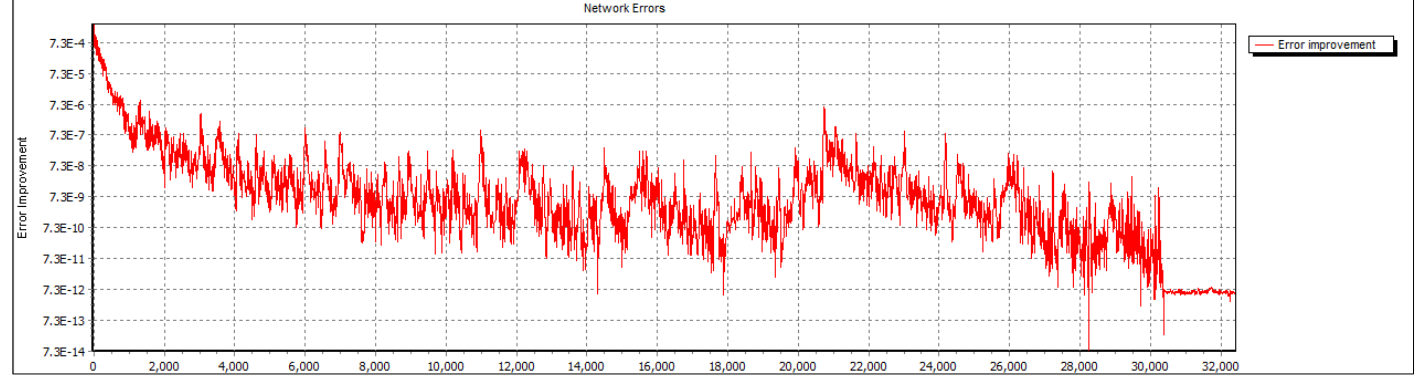

c)

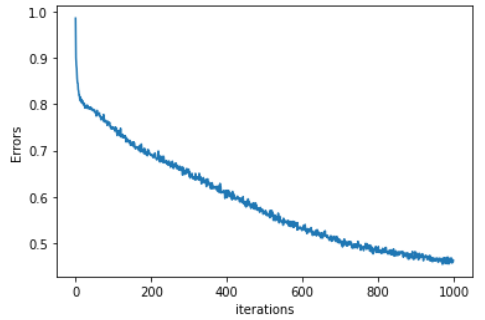

d)

Figure 2. Network training results. Error improvement: a) Quick propagation algorithm; b) Levenberg-Marquardt algorithm; c) Quasi-Newton; d) MLP Source: Authors' simulation

The smaller the error the better the training is considered. The evolutions of the Quick propagation and MLP algorithms are smoother than the ones of the 
Leonardo Badea, Andreea-Daniela Moraru, Constantin Ilie, Cristina Duhnea, Iulian Panait

Levenberg-Marquardt and Quasi-Newton (we must emphasize the same learning rate for the first three algorithms, except for MLP). The progressions of the last two are more prone to local minima blockage and missing the best error of the training.

Table 3. Training results. Alyuda software and Python

\begin{tabular}{|c|c|c|c|c|c|c|c|c|}
\hline $\begin{array}{l}\text { No. } \\
\text { Crt. }\end{array}$ & $\begin{array}{c}\text { Training } \\
\text { algorithms }\end{array}$ & $\begin{array}{l}\text { CCR, \% } \\
\text { Training }\end{array}$ & $\begin{array}{c}\text { CCR, \% } \\
\text { Validation }\end{array}$ & $\begin{array}{l}\text { Network } \\
\text { Error }\end{array}$ & $\begin{array}{c}\text { Error } \\
\text { improvement }\end{array}$ & $\begin{array}{c}\text { No. of } \\
\text { iterations }\end{array}$ & $\begin{array}{c}\text { Training } \\
\text { speed, } \\
\text { iter/sec. }\end{array}$ & $\begin{array}{l}\text { Training } \\
\text { stop }\end{array}$ \\
\hline 1. & $\begin{array}{l}\text { Quick } \\
\text { propagation }\end{array}$ & 97.92 & 84.17 & 0.0125 & $2.41 \times 10^{-8}$ & 90536 & 126 & User brake \\
\hline 2. & $\begin{array}{l}\text { Levenberg- } \\
\text { Marquardt }\end{array}$ & 78.42 & 70.88 & 0.8093 & $3.23 \times 10^{-4}$ & 39 & 5 & $\begin{array}{c}\text { No error } \\
\text { improvement }\end{array}$ \\
\hline 3. & Quasi-Newton & 98.21 & 84.17 & 0.0097 & $5.66 \times 10^{-12}$ & 32385 & 38 & User brake \\
\hline 4. & $\begin{array}{l}\text { Python } \\
\text { Multilayer } \\
\text { Percepton }\end{array}$ & \multicolumn{2}{|c|}{$\begin{array}{c}\text { Training accuracy } \\
0.84\end{array}$} & 0.4395 & & 1598 & 44 & $\begin{array}{c}\text { No error } \\
\text { improvement }\end{array}$ \\
\hline
\end{tabular}

Source: Authors' simulation

Observing table 3, the best result from the maximum values of CCR, belongs to the Quasi-Newton and is very close to the Quick propagation. The Quasi-Newton has also the best error improvement (smallest). The weakest results belong to the Levenberg-Marquardt, and it seems that the local minima cannot be avoided totally as the number of iterations is too small, thus, the poor results in CCR and error improvement values. The MLP is situated close to the first two.

The confusion matrix is a technique for summarizing the performance of a classification algorithm (figure 3).

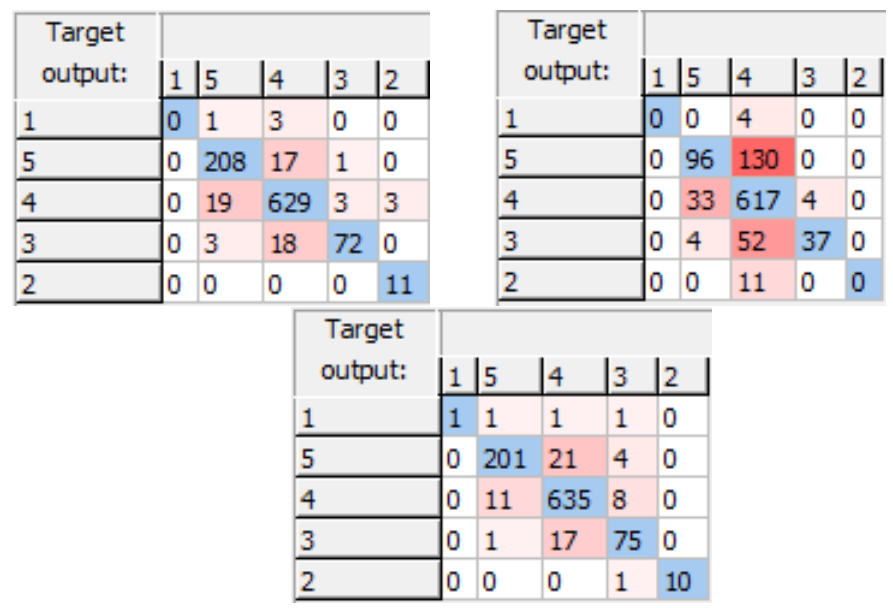

a)

b)

c) 
Customer Satisfaction with Banking Services. Simulating the Influence of Customer Satisfaction Determinants Using Artificial Neural Network Algorithms

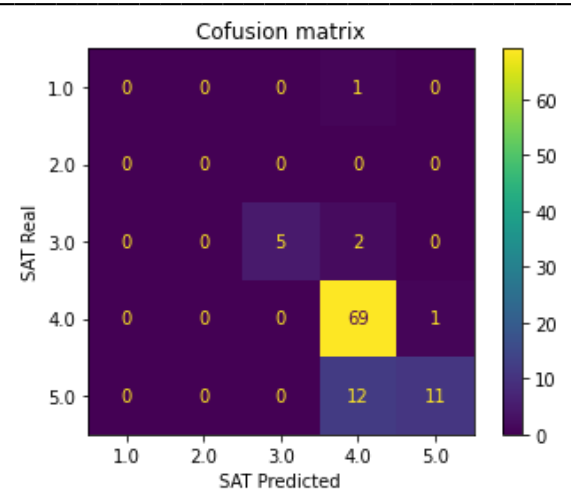

d)

Figure 3. Network training results. Confusion matrix: a) Quick propagation algorithm; b) Levenberg-Marquardt algorithm; c) Quasi-Newton; d) MLP Source: Authors' simulation

The authors decided to compare the results of the ANNs' training by applying them to a new set of data, never fed to the ANNs. The criterion for ranking is the ratio between the number of "good" predictions and the number of the new sets of data. In table 4 the results of the simulated results with these new data are shown.

\section{Table 4. External testing. Alyuda software and Python}

\begin{tabular}{|c|l|c|c|c|c|}
\hline $\begin{array}{c}\text { No. } \\
\text { Crt. }\end{array}$ & \multicolumn{1}{|c|}{$\begin{array}{c}\text { Training } \\
\text { algorithms }\end{array}$} & $\begin{array}{c}\text { No. of good } \\
\text { predictions }\end{array}$ & No. data & Ratio & Rank \\
\hline 1 & Quick propagation & 90 & 101 & 0.89 & I \\
\hline 2 & $\begin{array}{l}\text { Levenberg- } \\
\text { Marquardt }\end{array}$ & 78 & 101 & 0.77 & IV \\
\hline 3 & Quasi-Newton & 89 & 101 & 0.88 & II \\
\hline 4 & $\begin{array}{l}\text { Python Multilayer } \\
\text { Perceptron }\end{array}$ & 85 & 101 & 0.84 & III \\
\hline
\end{tabular}

Source: Authors'calculations

Based on the ranking presented in table 4, the most suitable algorithm for the data of the present research is the Quick propagation. The most influential input over the training results and, thus, over the values simulated for the outputs is the RAT (tariffs) component. The influence of tariffs on the general satisfaction with banking services is slightly over a quarter $(27.57 \%)$ of the entire input influence. The convenience and environment components' influences are almost at $19 \%$ each (19.86\% and $19.35 \%$ respectively) while the lowest influence was exhibited by quality and e-banking ( $16.31 \%$ and $16.90 \%$ respectively). This hierarchy confirms that the general satisfaction is rather influenced by the level of tariffs that the other components of the satisfaction construct. 
Leonardo Badea, Andreea-Daniela Moraru, Constantin Ilie, Cristina Duhnea, Iulian Panait

\section{Conclusions}

The current conditions brought customer satisfaction and its' determinants to the attention of bank management. The concern to develop and implement specific decision-making instruments with regard to customer satisfaction generated a plethora of approaches.

The present research focuses on customer satisfaction and a set of customer satisfaction determinants to reveal the directions for improving customer satisfaction with banking services, with a positive impact on the bank performance indicators. To this end, we compared four artificial neural network algorithms in order to determine which one is most suitable for the data. The results revealed that the Quick propagation and the Quasi-Newton algorithms are the algorithms with the best results in testing. These results can be explained by these two algorithms' features. The Limited Memory Quasi-Newton was chosen under the assumption it was fast, yet it was more than three time slower than Quick propagation. The rapid convergence (only 32385) and the evolution of the network error, provided evidence that the Quick propagation was best suited.The Levenberg-Marquardt algorithm did not have the right features and components useful tothis kind of data.The conclusion regarding Python is rather disappointing. The numerous trials to improve its result were useless. The utilization of identity, logistic functions and RELU and ADAM solvers led to even weaker results than the Limited Memory Quasi-Newton algorithm. The best results were obtained by reducing the learning rate and using the hyperbolic tan function and stochastic gradient descent solver. Also, the small number of iterations is a problem that must be attended to as we consider that the results of training and testing would became better with a longer training process.

The most influential input over the training results and, thus, over the values simulated for the outputs is tariffs parameter, with an influence of slightly over a quarter $(27.57 \%)$ of the entire input influence. The convenienceand environment influences are almost at $19 \%$ each (19.86\% and $19.35 \%$ respectively) and the lowest influence was shown by quality ande-banking $(16.31 \%$ and $16.90 \%$ respectively). The importance of e-banking in the assessment of global satisfaction is marginal according to our sample, which is surprising given the recent trends in customer preferences, the popularity of the topic and the high priority on the agenda of policy makers' everywhere. One explanation for this could be that the data was collected before the start of the COVID-19 pandemic, thus it does not include the acceleration in customer preference for online services and the increase in the digitalization trend among financial institutions (especially, but also in other areas of economy and society). This could signal that, further research is needed in this particular two areas linked with customer satisfaction. At the same time it could also imply that better communication from policy makers regarding the benefits and importance of digitalization and green finance may prove beneficial 
Customer Satisfaction with Banking Services. Simulating the Influence of

Customer Satisfaction Determinants Using Artificial Neural Network Algorithms

for increasing bank customer awareness regarding the topic that will for sure be part of the future normality in financial services after the COVID-19 pandemic.

Further research will consider the comparison of the training and testing results of Quick propagation with other algorithms, built in Python, from the deep learning family. Also, the MLP will be further tested with different features than the onescurrently used.

\section{REFERENCES}

[1] Bahia, K., Nantel, J. (2000), A Reliable and Valid Measurement Scale for the Perceived Service Quality of Banks.International Journal of Bank Marketing, 18(2): 84-91;

[2] Belás, J.\&Gabčová, L. (2016),The Relationship among Customer Satisfaction, Loyalty and Financial Performance of Commercial Banks. Ekonomie a Management, 2(1): 132-144;

[3] Belás, J.\&Gabčová, L. (2014),Reasons for Satisfaction and Dissatisfaction of Bank Customers. Study from Slovakia and the Czech Republic. International Journal of Entrepreneurial Knowledge, 2(1): 4-13;

[4] Casaló, L. V., Flavián, C.\&Guinalíu, M. (2008),The Role of Satisfaction and Website Usability in Developing Customer Loyalty and Positive Word-of-Mouth in the e-Banking Services. International Journal of Bank Marketing, 26(6): 399417, doi:10.1108/02652320810902433;

[5] Daniel, W.W.\& Cross, C.L. (2013),Biostatistics, A Foundation for Analysis in the Health Sciences (10th edition). Wiley;

[6] Dennis, J.\&Moré, J. (1977), Quasi-Newton Methods, Motivation and Theory. SIAM Review, Society for Industrial and Applied Mathematics, 19 (1): 46-89;

[7] Fahlman, S. (1999),An Empirical Study of Learning Speed in Back-

Propagation Networks. Carnegie Mellon University;

[8] Gan, C., Cohen, D.,Clemes, M., Chong, E. (2006), A Survey of Customer

Retention in the New Zealand Banking Industry. Banks and Bank Systems, 1(4): 83-99;

[9] Hallowell, R. (1996),The Relationships of Customer Satisfaction, Customer Loyalty, and Profitability: An Empirical Study. International Journal of Service Industry Management, 7(4): 27-42, doi:10.1108/09564239610129931;

[10] Ilie, M., Moraru, A.-D, Ghita-Mitrescu, S. (2017),The Hierarchical Determination of Customer Satisfaction with Banking Services Using an Artificial Neural Network. Transformations in business \& economics, 16(2A): 401-420; 
Leonardo Badea, Andreea-Daniela Moraru, Constantin Ilie, Cristina Duhnea, Iulian Panait

[11] Keisidou, E., Sarigiannidis, L., Maditinos, D.I., Thalassinos, E.I. (2013),Customer Satisfaction, Loyalty and Financial Performance: A Holistic Approach of the Greek Banking Sector. International Journal of Bank Marketing, 31(4): 259-288;

[12] Lourakis, M. (2005), A Brief Description of the Levenberg-Marquardt Algorithm Implemented by Levmar;Foundation of Research and Technology; [13] Moraru, A.-D., Duhnea, C. (2018a),E-banking and Customer Satisfaction with Banking Services. Strategic Management, 23(3), 3-9;

[14] Moraru, A.-D., Duhnea, C. (2018b),Assessing Customer Satisfaction with Banking Services Using 3D Mathematical Representation in Strengthening the Competitiveness of Enterprises and National Economies. Thematic collection of papers of international significance, Ed. B. Krstic, University of Nis, Serbia, 1937 ;

[15] Mylonakis, J. (2009),Bank Satisfaction Factors and Loyalty: A Survey of the Greek Bank Customers; Innovative Marketing, 5(1):16-25;

[16] Ozatac, N., Saner, T., Sen, Z. (2016), Customer Satisfaction in the Banking Sector: The Case of North Cyprus, Procedia Economics and Finance, 870-878; [17] Rust, R. T., Zahorik, A. J. (1993),Customer Satisfaction, Customer Retention, and Market Share; Journal of Retailing, 69(2):193-215, doi:10.1016/0022-4359(93)90003-2;

[18] SigitParawansa, D.A. (2018), Effect of Commitment and Customers' Satisfaction on the Relationship between Service Quality and Customer Retention in Rural Banks in Makassar, Indonesia; Journal of Management Development, 37(1):53-64,https://doi.org/10.1108/JMD-12-2016-0303; [19]Yilmaz, V., Ari, E.,Gürbüz, H. (2018), Investigating the Relationship between Service Quality Dimensions, Customer Satisfaction and Loyalty in Turkish Banking Sector: An Application of Structural Equation Model; International Journal of Bank Marketing, 36(3):423440,https://doi.org/10.1108/IJBM-02-2017-0037;

[20] The National Bank of Romania Statistics Interactive Database. www.bnr.ro - Annual report 2019;

[21] The Romanian National Institute of Statistics statistical database. http://statistici.insse.ro:8077/tempo-online/

[22] Constanta County Statistics Directorate. https://www.constanta.insse.ro/ [23] https://www.alyuda.com/product/neural-networks-software [24] https://scikit-learn.org/stable/index.html. 
Customer Satisfaction with Banking Services. Simulating the Influence of

Customer Satisfaction Determinants Using Artificial Neural Network Algorithms

Appendix 1

Descriptive statistics

\begin{tabular}{|c|c|c|c|c|c|c|}
\hline & $\begin{array}{c}\text { General } \\
\text { satisfaction }\end{array}$ & Convenience & e-banking & Environment & Quality & Tariffs \\
\hline Mean & 4.09 & 3.75 & 3.42 & 3.64 & 4.13 & 3.71 \\
\hline Median & 4 & 4 & 3.5 & 3.8 & 4.25 & 4 \\
\hline Max. & 5 & 5 & 5 & 5 & 5 & 5 \\
\hline Min. & 1 & 1 & 1 & 1 & 1 & 1 \\
\hline Std. Dev. & 0.631 & 0.787 & 1.208 & 0.809 & 0.661 & 0.964 \\
\hline Skewness & -0.730 & -0.566 & -0.566 & -0.570 & -0.907 & -0.403 \\
\hline Kurtosis & 5.503 & 3.023 & 2.474 & 3.184 & 4.512 & 2.767 \\
\hline $\begin{array}{c}\text { Jarque- } \\
\text { Bera }\end{array}$ & 382.77 & 58.42 & 71.07 & 60.83 & 254.37 & 32.01 \\
\hline Prob. & 0.000 & 0.000 & 0.000 & 0.000 & 0.000 & 0.000 \\
\hline Sum & 4476 & 4106.5 & 3746 & 3978.6 & 4522.25 & 4063 \\
\hline $\begin{array}{c}\text { Sum Sq. } \\
\text { Dev. }\end{array}$ & 434.86 & 676.11 & 1595.7 & 715.2 & 477.39 & 1015.45 \\
\hline Obs. & 1094 & 1094 & 1094 & 1094 & 1094 & 1094 \\
\hline
\end{tabular}

